\title{
SUPERGRUPO ESPINHAÇO: MODELO DE EVOLUÇÃO GEODINÂMICA
}

\author{
Ivo Antônio Dussin(*) \& Tânia Mara Dussin (*)
}

\begin{abstract}
The São Francisco Craton in Eastern brazil, one of the major shield areas forming the South American Platform, had its present-day configuration defined by the remobilisation of its edges during the Brasiliano orogeny in the Neoproterozoic. This tectonic event produced deformation and closure of the Middle to Neoproterozoic basins represented in the neighbouring craton regions. In the south-east boundary area of the craton, the Espinhaço Supergroup, a thick metasedimentary sequence, represents one of these basins. This region has a long tectonic history. About $1.7 \mathrm{Ga}$, after the Paleoproterozoic period of deformation and igneous activity of the Transamazonian Orogeny, the crust was affected by an extensional event which resulted in fragmentation and development of a rift basin where the Espinhaço Supergroup was deposited. About $900 \mathrm{Ma}$, a second extensional event represented by emplacement of mafic dikes in areas adjacent to the craton and formation of a new rift basin toward East is represented. The tectonic evolved into continental collision producing crustal shortening and thickening with westward tectonic transport onto the craton.
\end{abstract}

\section{INTRODUÇÃO}

A formação de bacias sedimentares continentais é um critério maior e característico da existência de tectônicas extensivas no interior de placas. Na região do Espinhaço em Minas Gerais, sôbre a borda sudeste do Craton São Francisco, as bacias do Mesoproterozóico constituem a resposta à fôrças distensivas que afetaram a crosta após a orogênese transamazônica. Estes episódios extensionais precederam a tectônica brasiliana (650-550 Ma), a qual representou uma inversão tectônica dos movimentos que conduziram à deformação das bacias e à estruturação da Faixa Araçuaí.

Este longo período entre as duas orogêneses é mal conhecido. Novos dados sôbre o magmatismo, a deformação e a geocronologia constituem importantes argumentos aos modêlos de evolução tectônica regional e fontes de informação sôbre a natureza da crosta e do manto proterozóicos. Integrados ao conhecimento geológico disponível, êles permitem propor um modelo para a evolução da região após os eventos de deformação do Paleoproterozóico.

\section{FORMAÇÃO DA BACIA ESPINHAÇO}

Durante o Mesoproterozóico, um sistema de forças em regime extensivo conduziu a um adelgaçamento da litosfera continental que se traduziu nas partes superiores desta pela ruptura e a fraturação da crosta frágil. Desenvolveu-se então um processo de rifting que resultou na instalação de uma ampla bacia de extensão submeridiana onde se depositou o Supergrupo Espinhaço (Fig. 1a).

Espêssas camadas de quartzitos com conglomerados e intercalações de sericita-xistos constituem o Supergrupo (Pflug \& Renger, 1973; Schöll \& Fogaça, 1979; Garcia \& Uhlein, 1987). Estes metasedimentos foram divididos em oito formações (Pflug, 1968), reunidas nos Grupos Diamantina e Conselheiro Mata (Dossin et al., 1990).

\section{(a). Fase Rift (a 1,7 Ga)}

A sequência basal do Supergrupo Espinhaço, Grupo Diamantina - uma série de sedimentos terrígenos característicos de ambientes fluviais entrelaçados , deltáico e marinho pouco profundo (Garcia \& Uhlein, op.cit.) foi depositada durante a fase rift principal. As características da sedimentação no contexto das formações basais, São João da Chapada e SopaBrumadinho, especialmente a frequência e rapidez das variações faciológicas verticais e laterais, indicam uma grande instabilidade da bacia que é típica deste período. Os litotipos mais frequentes são quartzitos com intercalações de metasiltitos, filitos e conglomerados, localmente diamantíferos. Estes sedimentos foram cobertos por quartzitos de ambientes eólico e marinho raso (Formação Galho do Miguel) que correspondem à parte superior da sequência e que registram o fim da instabilidade crustal neste período.

Rochas vulcânicas ocorrem na porção inferior do Grupo Diamantina, cortando ou intercaladas com a sequência sedimentar. As relações estratigráficas indicam que o vulcanismo começou num estágio precoce da bacia e esteve ativo durante a sedimentação das formações São João da Chapada e SopaBrumadinho. As rochas vulcânicas ocorrem preenchendo diques verticais de direção NS e EW que cortam o embasamento ou como derrames de lavas com intercalações de tufos. A mineralogia destas rochas é 


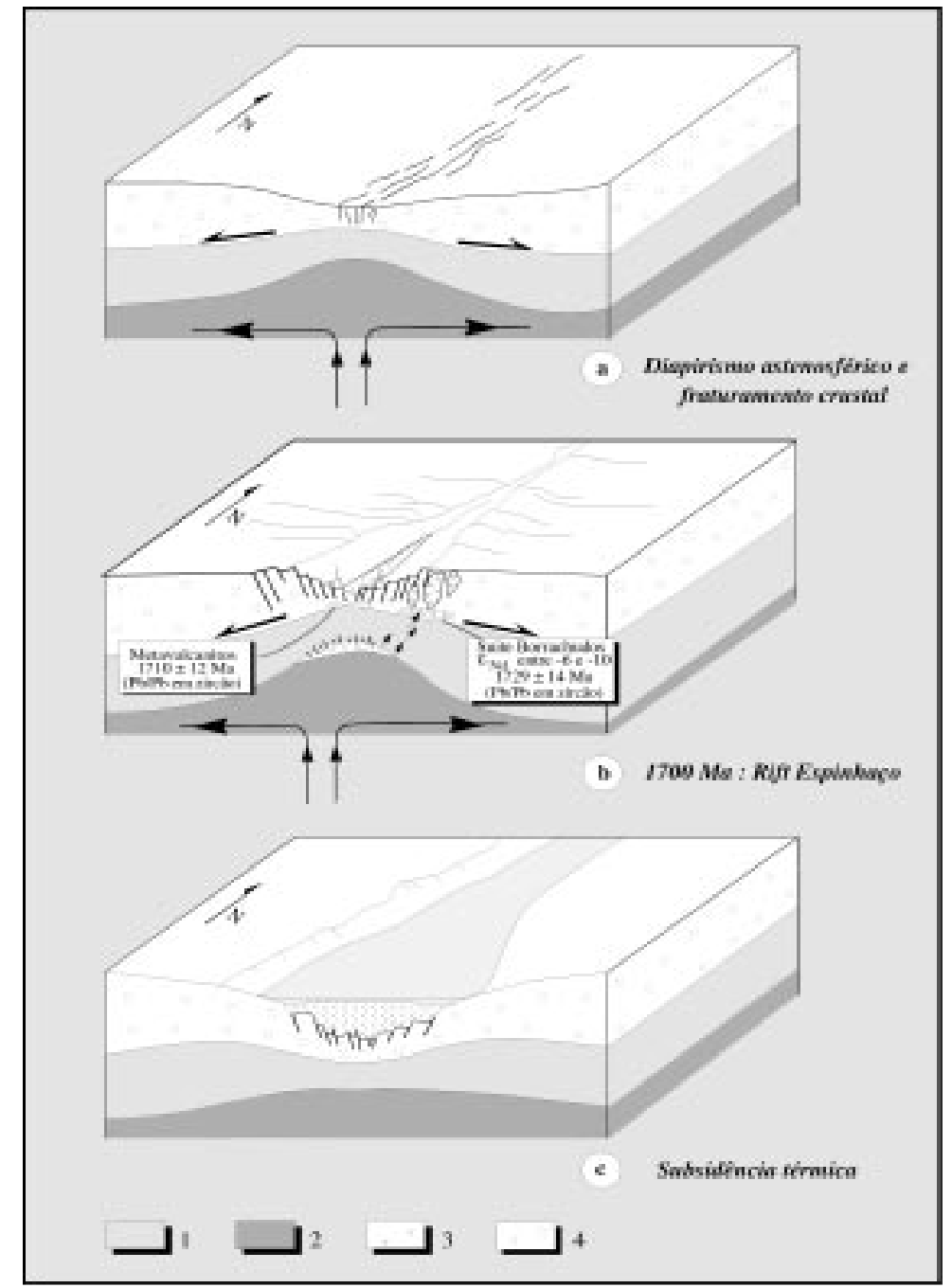

Figura 1: Representação esquemática da evolução geodinâmica do Espinhaço Meridional. (1) Litosfera; (2) Astenosfera; (3) Zona de fusão parcial e (4) Crosta

Figure 1:

essencialmente metamórfica com xistos ricos em sericita e óxidos de Fe-Ti e subordinadamente cloritaxistos, substituindo os minerais magmáticos que são encontrados sob forma reliquiar. As feições texturais indicam rochas diferentemente deformadas com desenvolvimento de uma foliação milonítica NE mergulhando para SE em zonas de altostress. Em zonas de menor stress, texturas e estruturas primárias podem estar localmente preservadas. A despeito da forte alteração secundária a que estas rochas foram submetidas, suas feições geoquímicas em termos dos elementos menos móveis, especialmente Zr, Y e REE indicam rochas de filiação alcalina como protólitos magmáticos (Dussin et al., no prelo). Uma determinação isotópica $\mathrm{Sm} / \mathrm{Nd}$ é disponível para as metavulcânicas enriquecidas em Fe-Ti: elas fornecem uma ${ }^{147} \mathrm{Sm} /{ }^{144} \mathrm{Nd}=0,11909$ e $\varepsilon_{\mathrm{Nd} 1710 \mathrm{Ma}}=-0,997$. Embora um único dado exclua a possibilidade de interpretações conclusivas e qualquer informação sôbre a heterogeneidade da sequência seja perdida, este dado é compatível com a caracterização de magmas primários de trend alcalino gerados a partir da fusão de fontes magmáticas de natureza condrítica.

Estudos geocronológicos baseados em determinações $207 \mathrm{~Pb} / 206 \mathrm{~Pb}$ pelo método de evaporação do $\mathrm{Pb}$ sôbre zircões das metavulcânicas foram recentemente realizados. Os resultados obtidos indicam idades de cristalização da rocha de $1710 \pm 12$ Ma (Dussin et al., no prelo). Esta idade é interpretada como o período inicial das atividades magmáticas e da deposição do Supergrupo Espinhaço.

A idade obtida para as metavulcânicas indica que o vulcanismo que acompanhou a sedimentação inicial do rift foi contemporâneo à intrusão de magmas graníticos nas bordas da bacia em formação. Resultados geocronológicos recentes sôbre os granitos Borrachudos, um conjunto de plutons que intrudiu o embasamento a sudeste da Faixa Araçuaí, indica para estas rochas idades de $1729 \pm 12$ Ma (determinações $207 \mathrm{~Pb} / 206 \mathrm{~Pb}$ pelo método de evaporação do $\mathrm{Pb}$ em zircões segundo Dossin et al., 1993). Estas rochas representam os equivalentes plutônicos dos riolitos que 
se intercalam tectonicamente à sequências metasedimentares dentro da faixa de dobramento (Dussin, T.M., 1994) e que tem idades bem conhecidas variando entre 1711 e $1770 \mathrm{Ma}$ ( U/Pb sôbre zircões, dados de Brito Neves et al., 1979 e Machado et al., 1989) extendendo a êles a designação de Borrachudos. Granitos e riolitos Borrachudos tem um carater metaluminoso a subalcalino e são similarmente enriquecidos em K, Fe, Nb, Y, Zr, Ga e REE. Estas feições geoquímicas associadas a suas composições isotópicas de $\mathrm{Nd}$ (eNd1730 Ma entre -10,1 e -6,2) e de $\mathrm{Sr} \quad(87 \mathrm{Sr} / 86 \mathrm{Sr}$ inicial=0,7057) atestam a comagmaticidade destas rochas e indicam gênese de magmas por fusão parcial de fontes crustais empobrecidas (Dussin, T. M., op.cit.). O conjunto das características petrográficas e geoquímicas dos Granitos Borrachudos colocam em evidência suas grandes analogias com os granitos do Tipo A intrudidos em contexto anorogênico intraplaca.

A correlação cronológica entre estes episódios magmáticos de natureza distinta é reveladora do contexto geotectônico de deposição do Supergrupo Espinhaço. Durante o evento extensional, o adelgaçamento litosférico teria induzido um levantamento da astenosfera levando à fusão por descompressão das fontes mantélicas e à geração dos magmas alcalinos que alimentaram o rift. Magmas de natureza kimberlítica foram provavelmante gerados neste período e intrudidos na crosta como sugerido pela presença de ocorrências diamantíferas associadas aos conglomerados da Formação Sopa-Brumadinho (Dossin et al., 1990). O levantamento da astenosfera parece ter, adicionalmente, fornecido a energia necessária à fusão de fontes crustais de natureza refratária e geração dos magmas Borrachudos (Fig. 1b).

Associações similares de sequências sedimentares de caráter continental com granitos e riolitos ricos em álcalis são conhecidos em outras partes do escudo brasileiro. Estas associações tem sido descritas sôbre o Craton São Francisco, na região central da Bahia, nas regiões central e nordeste do Brasil assim como sôbre o Craton Amazônico (Pimentel et al., 1991; Sá, 1991; Dussin T.M., 1994) (Fig.2). No seu conjunto, estas ocorrências configuram um extenso cinturão de dimensões continentais relacionado à fraturação de uma crosta de natureza frágil entre cêrca de 1,9 e 1,7 Ga.

\section{(b). Fase pós-Rift (?)}

Em direção ao tôpo do supergrupo e para oeste, o Grupo Conselheiro Mata assinala condições gerais de tendência transgressiva em tôda a bacia numa fase de estabilidade tectônica. Litologicamente a unidade é uma sucessão de quartzitos, metassiltitos e filitos em alternância, sem registros de vulcanismo sinsedimentar.

A deposição da sequência ocorreu num contexto de subsidência do conjunto da bacia, o qual interveio posteriormente à sedimentação e ao magmatismo da fase rifting. A superfície da bacia afundou em relação ao nível do mar, provavelmente em consequência do reajuste crustal face ao decréscimo do gradiente térmico

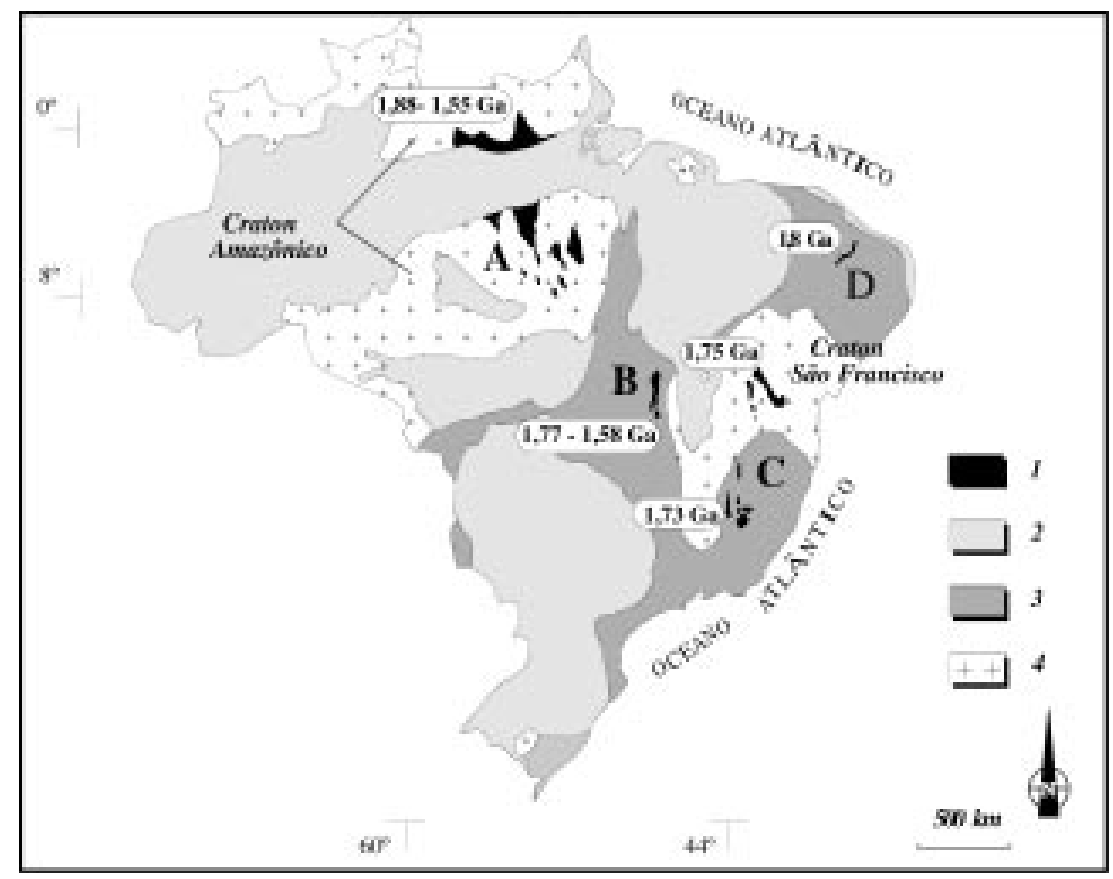

Figura 2: Distribuição das principais províncias granito-riolíticas do Proterozóico Médio-Inferior no Craton brasileiro (modificado de Pimentel et al., 1991). As Suites mostradas representam: A - Província AmazônicaCentral; B - Brasil-Central; C - Supergrupo Espinhaço e D - Sequência Orós. (1) Suites Graníticas; (2) Bacias Sedimentares Paleozóicas Faixas do Proterozóico Superior e (4) Áreas cratônicas no Proterozóico Superior.

Figure 2: 
crosta-manto em profundidade, e os sedimentos se acumularam em contexto marinho transgressivo (Fig. 1c).

A idade deste episódio de sedimentação é ainda desconhecida. Do ponto de vista sedimentológico, as diferenças de características dos depósitos bem como a presença de discordâncias erosivas locais, que separam as sequências rift e pós-rift, implicam na existência de um período de tempo ao longo do qual a deposição de sedimentos não ocorreu. No momento, nenhum referencial estratigráfico ou geocronológico permite precisar a duração deste intervalo não mais que a idade real da sequência.

\section{O RIFT ARAÇUAÍ ( $\approx 900$ MA)}

No início do Neoproterozóico, em tôrno de 900 Ma, um segundo período de extensão crustal afetou a região.

Nas regiões adjacentes ao Craton, as taxas de extensão foram pequenas e a fraturação crustal foi sinalizada apenas pela intrusão de diques de afinidade toleítica, que cortam todas as sequências do Supergrupo Espinhaço e seu embasamento. Não houve durante este período formação de vastas bacias de deposição nem têm sido reconhecidos derrames de lavas expressivos (Fig. 3a).

Mais a leste, as taxas de extensão crustal foram mais importantes e o depósito do Grupo Macaúbas, ao norte da região de Diamantina, testemunha o desenvolvimento de um novo processo de rifting. Em seu domínio oeste, o Grupo Macaúbas está composto por sedimentos glaciais litorâneos e por turbiditos de plataforma (Karfunkel \& Karfunkel, 1976). Estes sedimentos passam em direção leste para a Formação Salinas que é composta por uma sucessão de metapelitos em alternância com metaconglomerados e de quartzitos depositados em contexto marinho (Pedrosa Soares et al., 1992; Noce et al., 1993). Nesta região, Pedrosa Soares et al. (1990) descrevem uma sequência constituída por metassedimentos químicos e detríticos (Facies Ribeirão da Folha), com

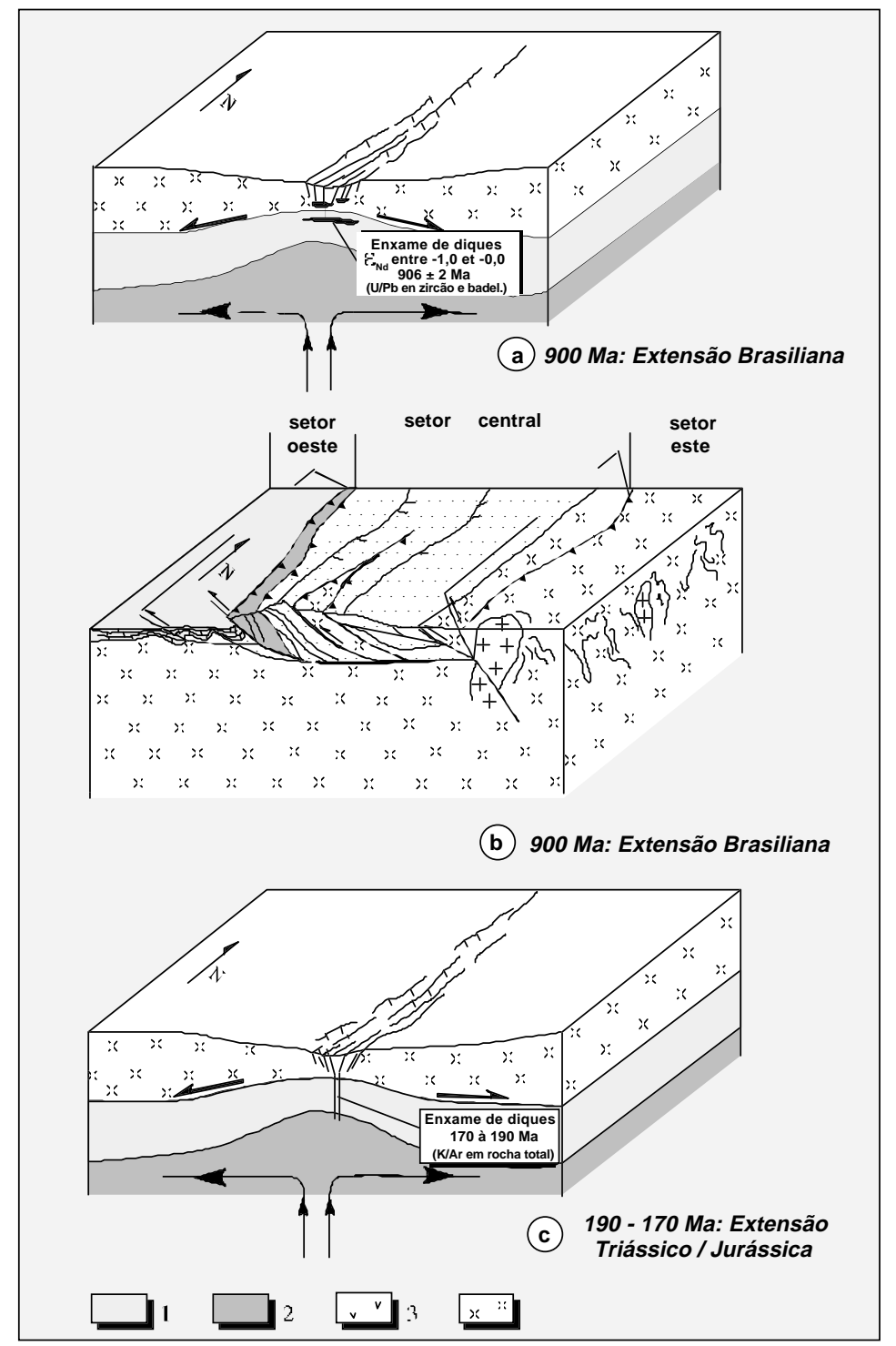

Figura 3: Representação esquemática da evolução geodinâmica do Espinhaço Meridional. (1) Listosfera; (2) Astenosfera; (3) Zona de fusão parcial; (4) Crosta.

Figure 3: 
intercalações tectônicas de rochas máficas e ultramáficas interpretadas como os testemunhos de crosta oceânica (Pedrosa Soares et al., 1992). Esta interpretação, representa uma contraposição aos modelos anteriormente propostos de evolução ensiálica para a Faixa Araçuaí (Hasui et al., 1978; Brito Neves \& Cordani, 1991) e implica que o limite oriental do bloco São Francisco teria evoluído, pelo menos em parte, em uma zona de acresção oceânica.

Este período de extenção e fraturação crustal faz parte de um processo generalisado de riftogênese que se desenvolveu em escala global, entre 1,1 e $0,9 \mathrm{Ga}$ afetando as regiões orientais e meridionais do Brasil e a porção ocidental da África Equatorial (Porada, 1989)(Fig. 4) e levando à fragmentação do hipotético continente Proto-Pangea (Sawkins, 1976; Piper, 1982). contexto de cisalhamento dúctil nas regiões orientais da Serra do Espinhaço até rochas não deformadas em direção ao interior do craton, a oeste. A análise das estruturas de deformação permite a distinção de três fases deformacionais distintas, das quais as duas primeiras tem caráter progressivo (Dussin, I.A., 1994). Durante a primeira fase compressiva o encurtamento crustal foi acomodado por grandes empurrões de direção norte-sul com uma geometria geral de rampas e patamares e o desenvolvimento de um sistema de duplex (Herrgesell \& Pflug, 1985; Uhlein et al., 1986; Marshak \& Alkmim, 1989; Chemale Jr. et al., 1992) afetando as sequências supracrustais e o embasamento. As dobras são diversamente representadas segundo a litologia e a localização dentro do cinturão. As dobras intrafoliais caracterizam as zonas de cisalhamento em

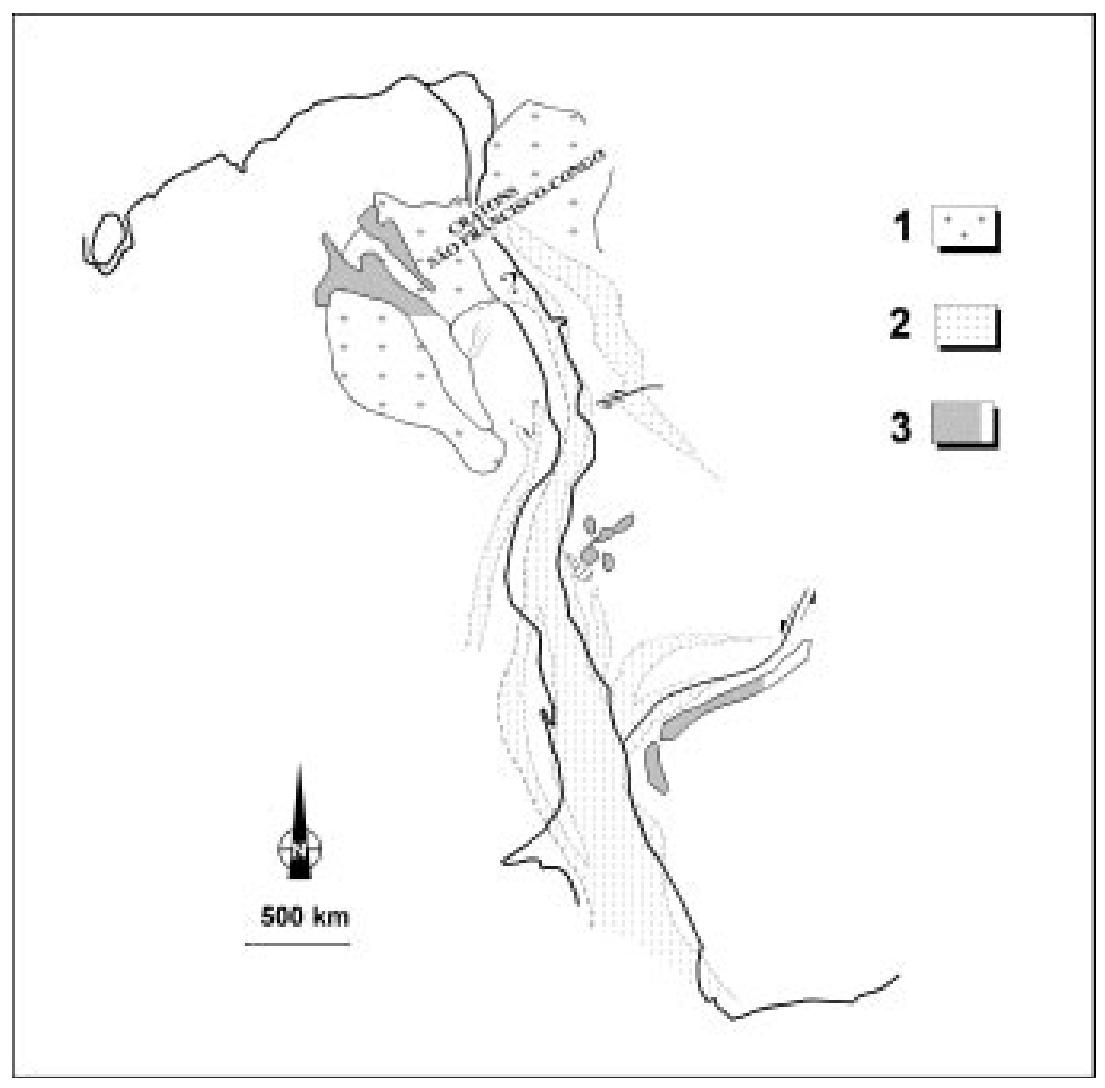

Figura 4: Configuração do sistema de fits Brasiliano e Pan-Africano deduzido a partir da distribuição de depósitos à leste do Brasil e África, numa reconstituição ante-deriva do Gondwana ocidental (modificado de Porada, 1989). (1) Área Cratônica; (2) Preenchimento do rift; (3) Rochas depositadas elou deformadas durante o Proterozóico Superior.

Figure 4:

\section{A TECTÔNICA BRASILIANA $(\approx \mathbf{6 5 0 - 5 5 0} \mathrm{MA})$}

No final do Neoproterozóico, a compressão brasiliana foi responsável pelo fechamento das bacias do Meso- e Neoproterozóico levando à estruturação da Faixa Araçuaí.

Os efeitos da orogênese brasiliana se traduzem por uma deformação regional que evolue a partir de um domínio dúctil. Uma foliação milonítica $\mathrm{S}_{1}$ de direção $\mathrm{N} 20^{\circ} \mathrm{E}$ e de mergulho $\mathrm{SE}$ e uma lineação $\mathrm{L}_{1}$ de caimento $\mathrm{N} 100^{\circ} \mathrm{E} / 30^{\circ}$ marcada por recristalização mineral, alongamento de seixos em conglomerados, rods nos BIF's, mullions de quartzo e eixos de dobras, são bem desenvolvidas nestes setores. Entre as zonas de cavalgamento, a deformação é menos intensa e marcada pela formação de dobras abertas e de uma clivagem de 
plano axial $\mathrm{N} 20^{\circ} \mathrm{E}$ e de mergulho SE. Nestas zonas, as estruturas primárias de rochas magmáticas e metassedimentares são, em geral, preservadas. O transporte tectônico em direção a oeste é demonstrado pela assimetria de dobras e boudins, pelas superfícies S/C, sombras de pressão e pela deformação de veios e fraturas de extensão. As condições metamórficas são de grau fraco, crescentes de anquimetamorfismo em regiões adjacentes ao craton até xisto verde nas regiões mais orientais do cinturão. A segunda fase de deformação é caracterisada por deformação e metamorfismo menos intensos e pela formação de dobras abertas associadas a uma clivagem $\mathrm{N}-\mathrm{S} / 60^{\circ} \mathrm{E}$ e lineações minerais N-S. Ondulações de eixo EW são superimpostas às estruturas mais antigas e registram a última fase de deformação. Os dados geocronológicos disponíveis obtidos sôbre granitos sin- e tardiorogênicos indicam idades entre 650 e 550 Ma para a fase tectônica principal (Siga Jr. et al., 1987; Teixeira, 1985). A caracterização das mesmas estruturas de deformação, dêsde a fase $\mathrm{D}_{1}$, nos metassedimentos do Supergrupo São Francisco, de idade Neoproterozóico, atesta a idade brasiliana desta deformação.

Entretanto, indícios de polimetamorfismo e a

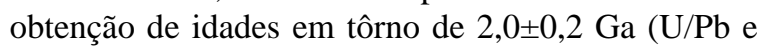
$\mathrm{Rb} / \mathrm{Sr}$ em rocha total segundo Teixeira, 1985 e Teixeira et al., 1990) demonstram um história evolutiva anterior. Na maior parte dos casos, a orogênese brasiliana apagou as estruturas mais antigas e os registros mais frequentes de eventos anteriores são fornecidos pela presença de relictos de paragêneses metamórficas mais antigas. A preservação de estruturas de deformação se dá sob a forma de relictos e é restrita aos setores da infraestrutura situadas sob as zonas de décollement (Dussin, I.A., 1994). Elas são representadas por dobras complexas, xistosidade e bandamento gnáissico $\mathrm{N} 10^{\circ} \mathrm{E} /$ subvertical e uma lineação mineral $\mathrm{N} 10^{\circ} \mathrm{E} / 50^{\circ}$. $\mathrm{O}$ metamorfismo associado a esta deformação é de alto grau (facies anfibolito superior) e foi acompanhado de migmatização e granitização no embasamento do craton e da faixa de dobramentos brasilianos.

Na região do Espinhaço Meridional, as condições de deformação e de metamorfismo da deformação brasiliana permitem distinguir pelo menos três setores distintos, caracterizados cada um por uma assinatura tectono-metamórfica própria. São eles: o Craton São Francisco a oeste, que funcionou como um ante-país, a região de Guanhães a leste e, entre estes dois blocos, o setor do rift Espinhaço (Fig. 3b). O limite entre os setores central e oriental parece ter coincidido, pelo menos em parte, com uma antiga descontinuidade crustal representada pelo lineamento N-S de expressão regional que encaixa o curso superior do Rio Guanhães. Esta estrutura coloca em contato duas porções de embasamento litologicamente distintas: gnaisses migmatíticos com intercalações de metassedimentos e granitos a leste, e biotita-gnaisses em sua maior parte de derivação sedimentar a oeste. O Bloco Oriental, ao contrário do Bloco Ocidental, se comportou de uma maneira rígida face à deformação, o que pode ser verificado através de uma análise da deformação dos granitos da Suite Borrachudos que pós-datam os elementos da orogênese transamazônica. Em efeito, estes granitos, com idades de 1,7 Ga, constituem as únicas rochas dentro do Bloco Oriental reconhecidamente posteriores aos eventos do Transamazônico e que portanto, foram submetidos exclusivamente à deformação brasiliana. Estes granitos apresentam estruturas e uma mineralogia primária notavelmente preservada, os únicos registros deformacionais sendo dados pela extinção ondulante do quartzo e, localmente, pela deformação das clivagens do feldspato.

Nesta porção da Faixa Araçuaí, a estruturação da serra indica que o seu fechamento se deu de maneira frontal (Herrgesell \& Pflug, 1985; Uhlein et al., 1986; Marshak \& Alkmin, 1989; Dossin et al., 1992). A coincidência por um lado da direção geral de trasporte tectônico quando da compressão e por outro lado o vetor das forças de extensão crustal revela que a orientação do sistema de forças permaneceu constante e apenas o módulo das forças foi submetido a uma perturbação.

No setor mais setentrional da Faixa Araçuaí a tectônica está marcada por uma cinemática de blocos mais complexos e a compressão se efetuou de maneira oblíqua segundo um deslocamento sinistro (Pedrosa Soares et al., 1992). Movimentos transcorrentes dextros de direção NE e expressão regional se formaram em resposta ao movimento relativo entre os diferentes blocos continentais. Pedrosa Soares et al. (1992) sugerem que esta zona de cisalhamento poderia representar o prolongamento daquela de Itabuna (Bahia) situada bem mais a NE, na costa brasileira. Nesta região, entre 650 e $550 \mathrm{Ma}$, maciços sieníticos foram intrudidos em sítios de transtensão associados à zonas de cisalhamento e foram a seguir deformados, durante o mesmo evento, em função da continuidade dos movimentos transcorrentes (Cordani \& Iyer, 1976; Pedreira, 1979). Esta zona de cisalhamento parece ter conhecido um desenvolvimento considerável e seu prolongamento tem sido descrito no continente africano onde ela sofreu, em torno de $660 \mathrm{Ma}$, a intrusão de carbonatitos, traquitos e lamprófiros do Complexo Mabounié no Gabão (Laval et al., 1988), o qual é sincrone às intrusões da província alcalina da Bahia. Dussin, T.M.(1994) descreve diques de lamprófiros no embasamento de Gouveia correlacionando-os a estes episódios magmáticos. Esta idéia é fundamentada pela natureza alcalina do conjunto destas rochas assim como pela sua posição, situadas no prolongamento do mesmo cinturão cisalhante (Fig. 5). Adicionalmente, a assinatura calco-alcalina dos lamprófiros de Gouveia e os valores preliminares de suas idades mínimas, em torno de 650 Ma (Dussin, T. M., op. cit.), vêm corroborar esta correlação.

A análise das estruturas brasilianas no conjunto da Faixa Araçuaí indica a existência de diferentes vetores de stress na região, que resultam provavelmente do 


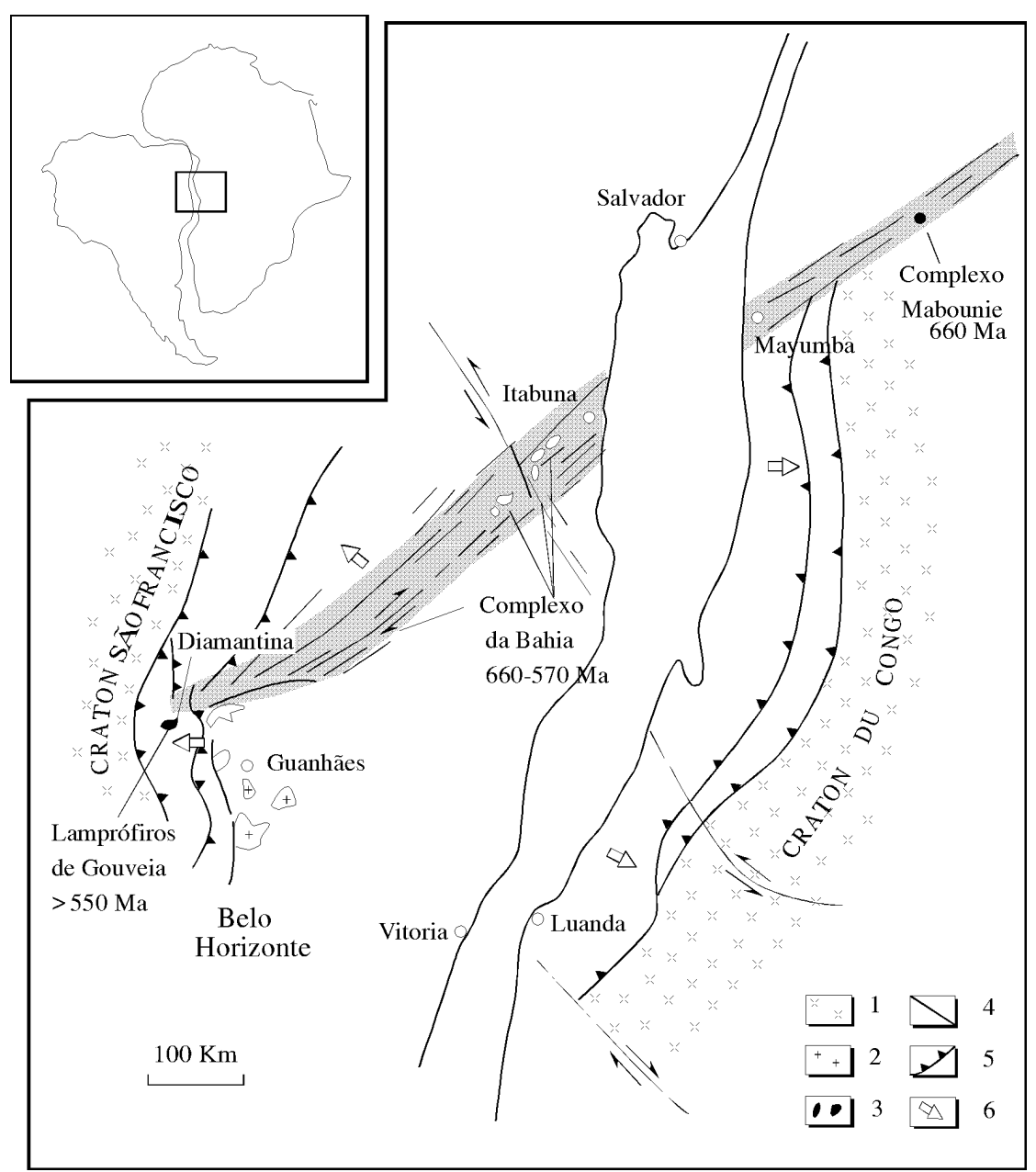

Figura 5: Mapa esquemático mostrando as estruturas maiores das Faixas Araçuaí-Oeste Congo na América do Sul e África, numa reconstituição pré-fragmentação, e localização das principais intrusões alcalinas intrudidas quando do principal período orogênico (modificado de Pedrosa Soares et al, 1992). (1) Área cratônica, (2) granitos, (3) complexos alcalinos, (4) transcorrências, (5) cinturões de cavalgamentos e (6) vergência tectônica

reajustamento de blocos continentais em resposta a um evento tectônico maior. De um ponto de vista mais amplo, a Orogênese Brasiliano-Pan-Africana teria se desenvolvido às margens de várias placas continentais que serviram de ante-país para os cinturões deste ciclo (Brito Neves \& Cordani, 1991).

\section{A EXTENSÃO DO CRETÁCEO (a 190-170 MA)}

No Fanerozóico, a presença de enxames de diques de basaltos de afinidade alcalina que cortam todas as unidades estratigráficas regionais, assim como as estruturas de deformação brasilianas, traduz um novo episódio de extensão crustal que constitui o último evento tectônico que afetou a borda oriental do Craton São Francisco (Fig. 3c).

As características petrográficas das rochas filoneanas que constituem um caráter distintivo dêste enxame em relação aos sistemas proterozóicos são principalmente a ausência de qualquer traço de deformação ou metamorfismo. Estes diques foram datados pelo método K/Ar em rocha total (Dussin et al., 1995) e os resultados obtidos indicam que sua intrusão foi associada à tectônica extensional do Mesozóico e relacionada a um período de atividade magmática coincidente com o limite Triássico Superior/ Jurássico Inferior, entre 220 e 170 Ma. Estas idades indicam que os diques analisados pertencem a um sistema que é anterior aos principais enxames e derrames fanerozóicos do sudeste do Brasil associados à abertura do Atlântico Sul e sua formação é relacionada à fragmentação inicial do Gondwana.

\section{REFERÊNCIAS BIBLIOGRÁFICAS}

Brito Neves, B.B. Kawashita, K. \& Delhal, J., 1979. A evolução geocronológica da Cordilheira do Espinhaço: dados novos e integração. Rev. Bras. Geoc., 9 (1): 71-85.

Brito Neves B.B. \& Cordani, U.G., 1991. Tectonic evolution of South America during the Late Proterozoic. Precamb.Res., 53: 23-40.

Chemale Jr., F., Alkmim, F.F. \& Endo, I., 1992. Late Proterozoic tectonism in the interior of the São Francisco Cráton., An. 
Gondwana Simp.(no prelo).

Cordani, U.G. \& Iyer, S.S., 1976. Comentários sôbre as determinações geocronológicas disponíveis na Folha Salvador SD-24. In: Carta Geológica do Brasil ao Milionésimo, Schobbenhaus C. (Ed.), Depart. Nac. Prod. Mineral, Brasília, 77-90.

Dossin, I.A., Dossin, TM. \& Chaves, ML S. C, 1990 . Compartimentač̃o estratigrífica do Supergrupo Espinhą

em Minas Gerais - os grupos Diamantina e Conselheiro Mata. Rev. Bras. Geoc., 20(1-4): 178-186.
Dossin, I.A., Dossin, T.M., Charvet, J. \& Chemale Jr., F., 1992. Tectonique du Protérozoïque supérieur au sud-est du Craton São Francisco (Minas Gerais, Brésil). C. R. Acad. Sci. Paris, 315-II, p.629-636.

Dossin, I.A., Dossin, T. M., Charvet, J., Cocherie, A. \& Rossi, P., 1993. Single-Zircon dating by step-wise $\mathrm{Pb}$-evaporation of Middle Proterozoic magmatism in the Espinhaço Range, southeastern São Francisco Craton (Minas gerais, Brazil). An. II Simp. Craton São Francisco, Salvador, p. 39-42.

Dussin, I.A., 1994. Evolution structurale de la region de l'Espinhaço Meridional, bordure Sud-est du Craton São Francisco Brésil. Tectoniques superposées au Protérozoïque. Tese de Doutorado, Univ. Orléans, 200p, (Inédito).

Dussin, T.M., 1994. Associations volcano-plutoniques de l'Espinhaço méridional (SE-Brésil): Un exemple d'évolution de la croûte Protérozoïque. Tese de Doutorado, Univ. Orléans, $177 \mathrm{p}$, (Inédito).

Dussin, T.M., Dussin, I.A., Charvet, J. \& Bonhomme, M.G., 1995. K-Ar Chronology of mesozoic dyke swarm from Southern Espinhaço Region (SE Brazil). J. South Amer. Earth Sci., 8 (1):47-54.

Dussin, T.M., Dussin, I.A., Rossi, P. \& Charvet, J. Dating of the Mesoproterozoic tensional event in the Espinhaço Range Southeastern of the São Francisco Craton (SE Brazil). J. South Amer. Earth Sci.(no prelo)

Garcia, A.J.V. \& Uhlein, A., 1987. Sistemas deposicionais do Supergrupo Espinhaço na região de Diamantina (MG). An Simp. Sistemas deposicionais do Pré-Cambriano, Ouro Preto, SBG-MG, 6:113-136.

Hasui, Y., Almeida, F.F.M. \& Brito Neves, B.B., 1978. As estruturas brasilianas. In: Congr.Bras.Geol., 30, Recife, 1978., Anais Recife, SBG, 6:2423-2437.

Herrgesell, G. \& Pflug, R., 1985. The thrust belt of the Southern Serra do Espinhaço, Minas Gerais, Brazil. Zbl. Geol. Palänt., 1(9/10): 1405-1414.

Karfunkel, B. \& Karfunkel, J., 1976. Estudos Petro-Faciológicos do Grupo Macaúbas na Porção Mediana da Serra do Espinhaço, Minas Gerais.XXIX Cong.Bras.Geol., Anais Ouro Preto-MG SBG, 2:179-188.

Laval, M., Johan, V. \& Tourlière, B., 1988. La carbonatite de Mabounié: Exemple de formation d'un gîte résiduel à pyrochlore. Chron. de la Rech. Min., 491: 125-136.

Machado, N., Schrank, A., Abreu, F.R., Knauer, L.G. \& Almeida Abreu, P.A., 1989. Resultados preliminares da geocronologia $\mathrm{U} / \mathrm{Pb}$ na Serra do Espinhaço Meridional. An V Simp. Geol. Núcleo M.G. and I Simp. Geol. Núcleo Brasília, SBG, Belo Horizonte, Bol. 10: 171-174.

Marshak, S. \& Alkmim, F.F., 1989. Proterozoic contraction/ extension tectonics of the southern São Francisco region, Minas
Gerais, Brazil. Tectonics, 8(3): 555-571.

Noce, C.M., Grossi, J.H., Pedrosa-Soares, A.C., Guimarães, M.L.V., Mourão, M.A.A., Oliveira, M.J.R. \& Roque, N.C., 1993. Litoestratigrafia do Grupo Macaúbas na Faixa Araçuaí, Minas Gerais., Submetido à Rev. Geonomos (IGC/UFMG).

Pedreira, A.J., 1979, Possible evidence of a Precambrian collision in the Rio Pardo Basin of the Eastern Brazil., Geology, 7: 445448.

Pedrosa-Soares, A.C.P., Monteiro, R.L.B.P., Noce, C.M., Freitas e Silva, F.H., Oliveira, M.J.R. \& Schettino, A., 1990. Caracterização de uma sequência vulcano-sedimentar distal da Faixa Araçuaí, MG: Bacia Oceânica Restrita ?, Bol.Res.XXXVI Cong.Bras.Geol.(Natal), 292

Pedrosa-Soares, A.C.P., Noce, C.M., Vidal, Ph., Monteiro, R.L.B.P. \& Leonardos, O.H., 1992. Toward a new model for the Late Proterozoic Araçuaí (SE Brazil) - West Congolian (SW Africa) Belt. J. of South Am. Earth Sci., 6(1/2): 33-47.

Pflug. R., 1968. Observações sobre a estratigrafia da Série Minas na região de Diamantina, Minas Gerais. Dep.

Nac. Prod. Min., Div. Geol. Min., Rio de Janeiro, Not.Prelim.Est., 142, 20p.
Pflug, R. \& Renger, F., 1973. Estratigrafia e evolução geológica da margem sudeste do Craton Sanfranciscano. An. XXVII Congr. Bras. Geol., Aracaju, 2:5-19.

Pimentel, M.M., Heaman, L., Fuck, R.A. \& Marini, O.J., 1991. U$\mathrm{Pb}$ zircon geochronology of Precambrian tin-bearing continental-type acid magmatism in central Brazil. Precambrian Res., 52: 321-335.

Piper, J.D.A., 1982. The Precambrian paleomagnetic record: The case for the Proterozoic supercontinent, Earth Planet.Sci.Lett., 59: 61-89.

Porada, H., 1989. Pan-African rifting and orogenesis in Southern to Equatorial Africa and Eastern Brazil, Precambrian Research, 44: $103-136$

Sá, J.M., 1991. Evolution geodynamique de la ceinture protérozoïque d'Orós, Nord-est du Brésil. Tese dout., Univ. Nancy, 177p, (Inédito).

Sawkins, F.J., 1976. Widespread continental rifting: some considerations of timing and mechanism, Geology, 4: 427-430.

Schöll, W.U. \& Fogaça, A.C.C., 1979. Estratigrafia da Serra do Espinhaço na região de Diamantina. In: Atas I Simp. de Geologia de Minas Gerais, Diamantina, SBG-MG, 1:55-73.

Siga Jr.,O., Cordani, U.G., Kawashita, K., Basei, M.A.S. \& Taylor, P.N., 1987. Aplicação dos isótopos de $\mathrm{Sr}$ e $\mathrm{Pb}$ nas rochas gnáissico migmatíticas de Itacambira-Barrocão. Anais $4^{\circ}$ Simp. Geol. de Minas Gerais, 7: 45-57.

Teixeira, W., 1985. A Evolução geotectônica da porção meridional do Craton São Francisco com base em interpretações geocronológicas. Tese de Doutorado, Univ. São Paulo, 207p.(Inédito)

Teixeira, W., Dossin I.A., Dossin, T.M., Salvador, E.D., Siga Jr.,O. \& Sato, K., 1990. Interpretação do contexto geotectônico do embasamento na borda leste do sistema Espinhaço, região de Guanhães e Gouveia-MG, com base numa integração do seu conjunto geocronológico U/Pb, $\mathrm{Rb} / \mathrm{Sr}$ e K/Ar. Anais XXXVI Cong. Bras. Geol., Natal, 6: 2711-2722.

Uhlein, A., Trompette, R.R. \& Egydio da Silva, M., 1986. Estruturação tectônica do Supergrupo Espinhaço na Região de Diamantina (MG). Rev. Bras. Geoc., São Paulo, 16(2): 212- 